\title{
Editorial: Extra-Oral Taste Receptors: Function, Disease and Evolution
}

\author{
Ronghua ZhuGe ${ }^{1 *}$, Eugeni Roura ${ }^{2 *}$ and Maik Behrens ${ }^{3 *}$ \\ ${ }^{1}$ Department of Microbiology and Physiological Systems, University of Massachusetts Medical School, Worcester, MA, \\ United States, ${ }^{2}$ Centre for Nutrition and Food Sciences, Queensland Alliance for Agriculture and Food Innovation, The \\ University of Queensland, St. Lucia, QLD, Australia, ${ }^{3}$ Leibniz-Institute for Food Systems Biology at the Technical University of \\ Munich, Freising, Germany
}

Keywords: chemosensing, taste receptors, TAS2R, sweet taste receptors, extraoral, disease

\section{Editorial on the Research Topic}

\section{Extra-Oral Taste Receptors: Function, Disease and Evolution}

Taste is one of the five "classic" senses and initiates in taste receptor cells in the oral cavity of humans and other mammals. However, taste receptors and the molecules responsible for tastant detection are also widely expressed throughout the body, and they are involved in a wide variety of functions in tissues and organs outside the mouth. In the gastrointestinal tract (GIT), sweet taste receptors (i.e., TAS1R2+TAS1R3 heterodimer) contribute to glucose sensing and energy balancing (Jang et al., 2007; Margolskee et al., 2007); umami and other amino acids receptors (i.e., TAS1R1+TAS1R3, mGluR1, mGluR4, CaSR, GPRC6A, GPR92) reflect on protein-related nutrients (Haid et al., 2012; San Gabriel and Uneyama, 2013; Steensels and Depoortere, 2018; Modvig et al., 2019; Roura et al., 2019); Bitter taste receptors (TAS2Rs) have been involved in GIT motility,

\section{OPEN ACCESS}

Edited and reviewed by: Geoffrey A. Head,

Baker Heart and Diabetes Institute, Australia

*Correspondence:

Ronghua ZhuGe

ronghua.zhuge@umassmed.edu Eugeni Roura

e.roura@uq.edu.au Maik Behrens

m.behrens.leibniz-lsb@tum.de

Specialty section:

This article was submitted to

Integrative Physiology,

a section of the journal

Frontiers in Physiology

Received: 16 September 2020 Accepted: 28 September 2020

Published: 30 October 2020

Citation:

ZhuGe R, Roura E and Behrens $M$ (2020) Editorial: Extra-Oral Taste Receptors: Function, Disease and Evolution. Front. Physiol. 11:607134. doi: 10.3389/fphys.2020.607134 hunger/satiety hormone secretion and innate immune responses to parasite infection (Wu et al., 2002; Glendinning et al., 2008; Janssen et al., 2011; Howitt et al., 2016; Serrano et al., 2016; von Moltke et al., 2016; Kok et al., 2018). In addition, TAS1Rs are found in the hypothalamus, the main organ involved in the control of food intake, responding to the nutritional status in mice (Ren et al., 2019). In the respiratory system, TAS2R activation increases airway ciliary beat frequency (Shah et al., 2009), but paradoxically relaxes airway smooth muscle (Deshpande et al., 2010; Zhang et al., 2013). In the genitourinary system, TAS2Rs participate in spermatogenesis (Li and Zhou, 2012) and mediate a reflex loop in the urethra, leading to bladder contraction (Deckmann et al., 2014). In the cardiovascular system, TAS1Rs and TAS2Rs were found in cardiac myocytes, the latter being upregulated following starvation (Foster et al., 2013). Intriguingly, the expression of TAS1Rs and TAS2Rs is altered under several pathological conditions, and their polymorphisms have been linked to several human disorders (Lee et al., 2012; Orsmark-Pietras et al., 2013).

This Research Topic provides a timely overview of the latest insights into the extra-oral taste receptors in health and disease. Nayak et al. provide a comprehensive and systematic review of the expression and function of TAS2Rs in different airway and lung cells. They discussed the diverse effects of TAS2Rs in mitigating various pathological features of asthma and highlighted specific opportunities for developing selective agonists for distinct TAS2R subtypes in the treatment of asthma. Grassin-Delyle et al. presented new evidence on the expression of TAS2Rs in human macrophages and demonstrated that the agonists of TAS2R3, 4, 5, 9, 10, 14, 30, 39, and 40 inhibit cytokine production induced by lipopolysaccharide. Their results expand the cell type expressing TAS2Rs in the lung and substantiate the idea that TAS2Rs may constitute new drug targets in inflammatory obstructive lung disease. Luo et al. evaluated the potential value of screening TAS2R agonists that relax smooth muscle based on the bitter flavors of Traditional Chinese medicines (TCM). The authors applied bioinformatics mining to TCM databases and discovered many bitter tastants from TCM, which can activate TAS2Rs, as new smooth muscle relaxants. Bloxham et al. highlighted current research on bitter taste receptors and their signaling cascade in the heart. They 
stressed the need further to study these receptors' functions in the heart and predicted that TAS2Rs may involve in unappreciated cardiac physiology.

Fat or fatty acids have been recognized as the triggers of a potential sixth taste in animals and humans. Similar to the TAS1R and TAS2R families, the receptors for fatty acids, e.g., CD36, GPR40 (FFAR1), GPR41 (FFAR3), GPR43 (FFAR2), GPR84, and GPR120 (FFAR4), are also expressed in many cell types throughout the body. In the GIT and hypothalamic nucleus, fatty acids act on these receptors to critically regulate energy balance by changing ingestive behavior, energy storage, and utilization (Blouet and Schwartz, 2010; Cvijanovic et al., 2016; Liu et al., 2016). Significantly, these receptors' sensitivity to fatty acids in obese individuals is lower than that in lean individuals. This may account for excess fat consumption in obese individuals and contribute to other diseases such as type 2 diabetes (Stewart et al., 2011; Ichimura et al., 2012; Precone et al., 2019). Le Foll updated the current understanding of hypothalamic fatty acids and ketone bodies sensing (i.e., FAT/CD36 and GPCRs) and enzymatic activity (e.g., LPL) in regulating food intake. In particular, the author highlights that the expression of FA sensors/transporters

\section{REFERENCES}

Blouet, C., and Schwartz, G. J. (2010). Hypothalamic nutrient sensing in the control of energy homeostasis. Behav Brain Res. 209, 1-12. doi: 10.1016/j.bbr.2009.12.024

Cvijanovic, N., Isaacs, N. J., Rayner, C. K., Feinle-Bisset, C., Young, R. L., and Little, T. J. (2016). Duodenal fatty acid sensor and transporter expression following acute fat exposure in healthy lean humans. Clin. Nutr. 36, 564-569. doi: 10.1016/j.clnu.2016.02.005

Deckmann, K., Filipski, K., Krasteva-Christ, G., Fronius, M., Althaus, M., Rafiq, A., et al. (2014). Bitter triggers acetylcholine release from polymodal urethral chemosensory cells and bladder reflexes. Proc. Natl. Acad. Sci. U.S.A. 111, 8287-8292. doi: 10.1073/pnas.1402436111

Deshpande, D. A., Wang, W. C., McIlmoyle, E. L., Robinett, K. S., Schillinger, R. M., An, S. S., et al. (2010). Bitter taste receptors on airway smooth muscle bronchodilate by localized calcium signaling and reverse obstruction. Nat. Med. 16, 1299-1304. doi: 10.1038/nm.2237

Foster, S. R., Porrello, E. R., Purdue, B., Chan, H. W., Voigt, A., Frenzel, S., et al. (2013). Expression, regulation and putative nutrient-sensing function of taste GPCRs in the heart. PLoS ONE 8:e64579. doi: 10.1371/journal.pone.0064579

Glendinning, J. I., Yiin, Y.-M., Ackroff, K., and Sclafani, A. (2008). Intragastric infusion of denatonium conditions flavor aversions and delays gastric emptying in rodents. Physiol. Behav. 93, 757-765. doi: 10.1016/j.physbeh.2007.11.029

Haid, D., Jordan-Biegger, C., Widmayer, P., and Breer, H. (2012). Receptors responsive to protein breakdown products in G-cells and D-cells of mouse, swine and human. Front. Physiol. 3:65. doi: 10.3389/fphys.2012.00065

Howitt, M. R., Lavoie, S., Michaud, M., Blum, A. M., Tran, S. V., Weinstock, J. V., et al. (2016). Tuft cells, taste-chemosensory cells, orchestrate parasite type 2 immunity in the gut. Science 351, 1329-1333. doi: 10.1126/science.aaf1648

Ichimura, A., Hirasawa, A., Poulain-Godefroy, O., Bonnefond, A., Hara, T., Yengo, L., et al. (2012). Dysfunction of lipid sensor GPR120 leads to obesity in both mouse and human. Nature 483, 350-354. doi: 10.1038/nature10798

Jang, H. J., Kokrashvili, Z., Theodorakis, M. J., Carlson, O. D., Kim, B. J., Zhou, J., et al. (2007). Gut-expressed gustducin and taste receptors regulate secretion of glucagon-like peptide-1. Proc. Natl. Acad. Sci. U.S.A. 104, 15069-15074. doi: $10.1073 /$ pnas.0706890104

Janssen, S., Laermans, J., Verhulst, P. J., Thijs, T., Tack, J., and Depoortere, I. (2011). Bitter taste receptors and alpha-gustducin regulate the secretion of ghrelin with functional effects on food intake and gastric emptying. Proc. Natl. Acad. Sci. U.S.A. 108, 2094-2099. doi: 10.1073/pnas.1011508108 in neurons, astrocytes, and tanycytes mediates the regulatory function. However, other aspects linked to obesity and/or Type 2 diabetes, such as the impact of inflammation on FA and ketone bodies sensing remain to be further investigated.

We believe this Research Topic provides an exciting overview of the extraoral taste receptors. Since these receptors mediate the critical functions of extraoral tissues and contribute to different diseases, we hope that this Topic will foster the discovery of new pharmaceutical therapeutics targeting these taste receptors for various human diseases and disorders.

\section{AUTHOR CONTRIBUTIONS}

RZ, ER, and MB co-wrote and approved this Editorial. All authors contributed to the article and approved the submitted version.

\section{ACKNOWLEDGMENTS}

We thank all authors, reviewers, and Frontiers Editorial staff for their contributions to this Research Topic.

Kok, B. P., Galmozzi, A., Littlejohn, N. K., Albert, V., Godio, C., Kim, W., et al. (2018). Intestinal bitter taste receptor activation alters hormone secretion and imparts metabolic benefits. Mol. Metab. 16, 76-87. doi: 10.1016/j.molmet.2018.07.013

Lee, R. J., Xiong, G., Kofonow, J. M., Chen, B., Lysenko, A., Jiang, P., et al. (2012). T2R38 taste receptor polymorphisms underlie susceptibility to upper respiratory infection. J. Clin. Invest. 122, 4145-4159. doi: 10.1172/JCI64240

Li, F., and Zhou, M. (2012). Depletion of bitter taste transduction leads to massive spermatid loss in transgenic mice. Mol. Hum. Reprod. 18, 289-297. doi: 10.1093/molehr/gas005

Liu, D., Archer, N., Duesing, K., Hannan, G., and Keast, R. (2016). Mechanism of fat taste perception: association with diet and obesity. Prog. Lipid Res. 63, 41-49. doi: 10.1016/j.plipres.2016.03.002

Margolskee, R. F., Dyer, J., Kokrashvili, Z., Salmon, K. S., Ilegems, E., Daly, K., et al. (2007). T1R3 and gustducin in gut sense sugars to regulate expression of Na+-glucose cotransporter 1. Proc. Natl. Acad. Sci. U.S.A. 104, 15075-15080. doi: 10.1073/pnas.0706678104

Modvig, I. M., Kuhre, R. E., and Holst, J. J. (2019). Peptone-mediated glucagonlike peptide-1 secretion depends on intestinal absorption and activation of basolaterally located Calcium-Sensing Receptors. Physiol. Rep. 7:e14056. doi: $10.14814 /$ phy2.14056

Orsmark-Pietras, C., James, A., Konradsen, J. R., Nordlund, B., Soderhall, C., Pulkkinen, V., et al. (2013). Transcriptome analysis reveals upregulation of bitter taste receptors in severe asthmatics. Eur. Respir. J. 42, 65-78. doi: 10.1183/09031936.00077712

Precone, V., Beccari, T., Stuppia, I., Baglivo, M., Paolacci, S., Manara, E., et al. (2019). Taste, olfactory and texture related genes and food choices: implications on health status. Eur. Rev. Med. Pharmacol. Sci. 23, 1305-1321. doi: 10.26355/eurrev_201902_17026

Ren, X., Zhou, L., Terwilliger, R., Newton, S. S., and de Araujo, I. E. (2019). Sweet taste signaling functions as a hypothalamic glucose sensor. Front. Integr. Neurosci. 3:12. doi: 10.3389/neuro.07.012.2009

Roura, E., Depoortere, I., and Navarro, M. (2019). Review: chemosensing of nutrients and non-nutrients in the human and porcine gastrointestinal tract. Animal 13, 2714-2726. doi: 10.1017/S1751731119001794

San Gabriel, A., and Uneyama, H. (2013). Amino acid sensing in the gastrointestinal tract. Amino Acids 45, 451-461. doi: 10.1007/s00726-012-1371-2

Serrano, J., Casanova-Mart,í, À., Depoortere, I., Blay, M. T., Terra, X., Pinent, M., et al. (2016). Subchronic treatment with grape-seed phenolics inhibits 
ghrelin production despite a short-term stimulation of ghrelin secretion produced by bitter-sensing flavanols. Mol. Nutr Food Res. 60, 2554-2564. doi: $10.1002 / \mathrm{mnfr} .201600242$

Shah, A. S., Ben-Shahar, Y., Moninger, T. O., Kline, J. N., and Welsh, M. J. (2009). Motile cilia of human airway epithelia are chemosensory. Science 325, 1131-1134. doi: 10.1126/science.1173869

Steensels, S., and Depoortere, I. (2018). Chemoreceptors in the gut. Annu. Rev. Physiol. 80, 117-141. doi: 10.1146/annurev-physiol-021317-121332

Stewart, J. E., Newman, L. P., and Keast, R. S. J. (2011). Oral sensitivity to oleic acid is asso-ciated with fat intake and body mass index. Clin. Nutr. 30, 838-844. doi: 10.1016/j.clnu.2011.06.007

von Moltke, J., Ji, M., Liang, H. E., and Locksley, R. M. (2016). Tuft-cell-derived IL-25 regulates an intestinal ILC2-epithelial response circuit. Nature 529, 221-225. doi: 10.1038/nature1 6161

Wu, S. V., Rozengurt, N., Yang, M., Young, S. H., Sinnett-Smith, J., and Rozengurt, E. (2002). Expression of bitter taste receptors of the T2R family in the gastrointestinal tract and enteroendocrine STC-1 cells. Proc. Natl. Acad. Sci. U.S.A. 99, 2392-2397. doi: 10.1073/pnas.042617699

Zhang, C.-H., Lifshitz, L. M., Uy, K. F., Ikebe, M., Fogarty, K. E., and Zhuge, R. (2013). The cellular and molecular basis of bitter tastant-induced bronchodilation. PLoS Biol. 11:e1001501. doi: 10.1371/journal.pbio.1001501

Conflict of Interest: The authors declare that the research was conducted in the absence of any commercial or financial relationships that could be construed as a potential conflict of interest.

Copyright (c) $2020 \mathrm{ZhuGe}$, Roura and Behrens. This is an open-access article distributed under the terms of the Creative Commons Attribution License (CC BY). The use, distribution or reproduction in other forums is permitted, provided the original author(s) and the copyright owner(s) are credited and that the original publication in this journal is cited, in accordance with accepted academic practice. No use, distribution or reproduction is permitted which does not comply with these terms. 